\title{
A arquitetura da informação e as metas de experiência do usuário no contexto da práxis de construção dos elementos gráficos de interface para web
}

The architecture of information and the goals of user experience in the context of praxis construction related for web graphics interface

\section{SCHULENBURG, Haro Ristow Wippel, Doutorando em Design \\ Universidade Federal de Santa Catarina I UFSC haro@harodesigner.com.br}

\section{FIALHO, Francisco Antônio Pereira,Doutor}

Universidade Federal de Santa Catarina I UFSC fapfialho@gmail.com

\section{VELA, João Carlos}

Universidade Federal de Santa Catarina I UFSC joao.vela1@gmail.com

\section{ANGEOLETI,Larissa, Especialista}

Universidade da Região de Joinville I UNIVILLE larissa.angeoleti@gmail.com

\section{Resumo \\ O homem contemporâneo habituou-se a \\ Abstract} desenvolver cada vez mais a tecnologia de equipamentos que se tornaram suas próprias extensões e passaram a ter por consequência, uma necessidade maior na relação entre essas extensões. Neste âmbito que está inserido a importância do estudo de arquitetura da informação e metas de experiência do usuário. Conhecer e saber como transmitir a informação para este usuário é, talvez, o grande ponto de equilíbrio no contexto com a disposição dos elementos gráficos de uma interface. Para tanto foi feito uma revisão sistemática bibliográfica destes temas e suas relações e, por fim, um estudo de caso analisando a geração destes contextos em que a interface gráfica está inserida.

Palavras-Chave: Arquitetura da informação. Experiência do usuário. Elementos gráficos. Interface gráfica.

Modern man has become accustomed to develop increasingly tech equipment that have become their own extensions and now have consequently a greater need in the relationship between these extensions. In this context it is inserted in the importance of the study of information architecture and user experience goals. Know and how to convey the information for this user is, perhaps, the greatest equilibrium in context with the layout of the graphics of an interface. For this was made a systematic literature review of these issues and their relationships and finally a case study analyzing the generation of these contexts in which the graphic interface is inserted.

Keywords: Information architecture. User experience. Graphics. Graphical interface. 


\section{INTRODUC̣̃̃O}

Para Moura (2006, p. 4) "a interação do usuário com o sistema se dá através da conexão com nós e links, bem como através das ferramentas que possibilitam acessar as imagens, os sons, os textos". Pode-se dizer que as interfaces gráficas se traduzem nos sistemas de interação dispostas ao usuário. Nesse sentido, a abordagem da arquitetura de informação e os princípios de metas para experiência do usuário, contribuem para construção de uma interface gráfica e podem auxiliar o designer gráfico a traduzir esses sistemas de interação de forma coerente, fazendo com que o usuário julgue de forma clara e coerente.

Ao desenvolver uma interface gráfica, o designer depara-se com o este problema do julgamento: uma interface gráfica ruim, boa, infantil, séria, triste, atraente. De fato toda interface gráfica, sempre convida a um julgamento, porém esse nasce da própria interface e não de interpretações subjetivas ou opiniões. Uma interface gráfica não representa, mas apresenta várias características que por serem imaginais, sugerem uma virtualidade que transcende a realidade representada material e concreta. A interpretação de uma interface gráfica não é facilmente compreendida completamente, por isso exige trabalho e pesquisa do designer em suas etapas de construção para representá-la de maneira adequada.

Uma interface gráfica deve, então, suscitar elementos pertinentes aos usuários, no sentido de proporcionar dinamismo e facilidades para a navegação. Buscando-se alcançar uma interatividade que acontece naturalmente, já que computador e homem estão diretamente e intimamente ligados, tal como uma simbiose. Assim como escrevem Rosa e Moraes (2008, p. 13), existe, então, "uma relação simbiótica, na qual cada um amplia as capacidades do outro, na realização de tarefas complexas e multifacetadas".

\section{Arquitetura da Informação}

A disponibilização de informação em um meio exige uma organização desse conteúdo, de modo a garantir o acesso das pessoas. Imaginar uma rede, como a Internet, sem essa preocupação é o mesmo que imaginar que todos os livros do mundo estivessem num só livro sem sumário. Encontrar o que se busca seria uma tarefa árdua nesse "mar de tanta informação" (ROSA; MORAES, 2008).

O usuário deve percorrer caminhos curtos, entendendo onde ele está e 
para onde pode ir, ou seja, dentre a quantidade de informações e a variedade de ferramentas e elementos disponíveis, a existência de uma organização que viabilize a navegação guiada é necessária para que o usuário tenha visibilidade e saiba utilizar o sistema e se localizar (ANDRADE, 2007).

Em função disso, o constante crescimento da informação disponibilizada na rede, juntamente com o aumento da quantidade de pessoas conectadas, demonstram a importância que a arquitetura da informação vem apresentando (MEMÓRIA, 2003).

Conforme Rosa e Moraes (2008), a arquitetura da informação possibilita que os usuários encontrem intuitivamente o que precisam por meio da combinação de navegação com procura aplicada às estradas da informação e aos atalhos, pontes e conexões, construídos pelo arquiteto da informação.

Os designers de interface são também arquitetos da informação, fazendo com que a arquitetura seja acessível (LYNCH; HORTON, 2004). Fuentes (2006) acredita que por se tratar da escolha de navegação e interação adequadas, o designer de interface exerce maiores funções com a arquitetura da informação do que com gráficos.

Dessa forma, o designer gráfico participa ativamente no processo de desenvolvimento da arquitetura da informação e por isso é um assunto pertinente à concepção de uma interface gráfica.

A arquitetura da informação precisa ser bem projetada para garantir que as tarefas executadas pelos usuários sejam concluídas, poupando seu tempo e evitando que fiquem frustrados por não encontrarem o que buscavam (MEMÓRIA, 2003). Para garantir a eficiência nesse processo, a modelagem e a representação da arquitetura competem, segundo Rosa e Moraes (2008), a definição de um vocabulário de termos padronizados visando obter consistência ao longo do conteúdo e um mapa metafórico objetivando a representação da sua estrutura.

A figura 1 demonstra um mapa do tipo pente, útil para os meios que funcionam verticalmente, como neste documento. 
Figura 1 - Mapa em Pente

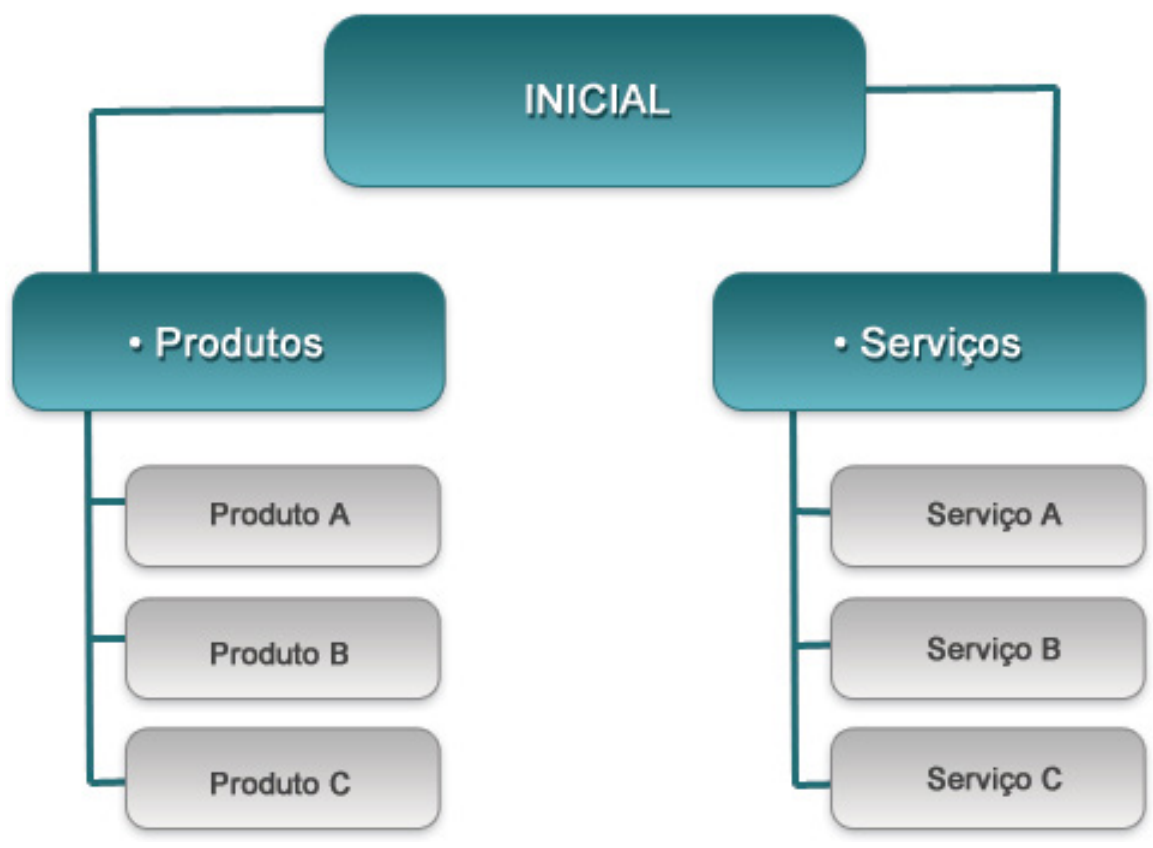

Fonte: Adaptado de Rosa e Moraes (2008, p. 82).

O mapa é descrito por Domingues (2002) como um fluxograma de navegação que permite circular pelas informações, como formas, sons e textos, disponíveis nas arquiteturas da hipermídia. Todavia, estes elementos não devem ser pensados durante a concepção da arquitetura da informação. Cabe, nesta etapa, apenas a tarefa de planejar uma estrutura informacional que seja intuitiva e por isso condicione ao usuário a capacidade de entender o caminho a ser percorrido para encontrar o que ele busca no meio virtual.

\section{Metas de Experiência do Usuário}

Segundo Preece, Rogers e Sharp(2007), o objetivo do desenvolvimento de projetos interativos está na experiência que será proporcionada para o usuário. Sendo assim, algumas características se apresentam, tais como: agradável; divertido; esteticamente apreciáveis; emocionalmente adequados que possuem a necessidade de estar na lista de requisitos de um projeto de interface gráfica. Estas características não são claramente definidas, elas são descobertas em estudos prévios focados no público alvo e devem ser levadas em conta na produção de projetos interativos.

Royo (2008) sugere cinco princípios para que um sistema seja útil e fácil de usar mostrados na figura 2. 
Figura 2 - Cinco Princípios de Usabilidade para Experiência do Usuário

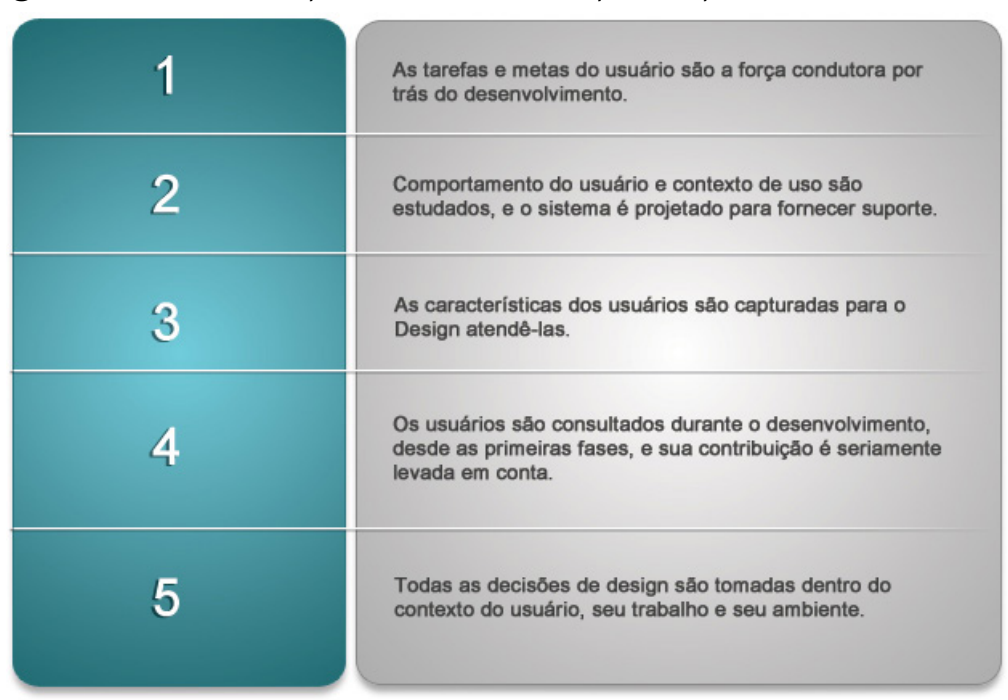

Fonte: Adaptado de Royo (2008).

Ainda de acordo com Royo (2008) a experiência do usuário é um conjunto da experiência funcional juntamente com a experiência estética do produto. E que ela, a experiência do usuário, é resultado dos objetivos do usuário, das variáveis culturais e do design de interface gráfica.

As variáveis culturais dependerão do conhecimento que o usuário tem de interfaces similares, e segundo Royo (2008, p. 105) "o usuário busca os conhecimentos em sua própria mente (conhecimento de mente) e no mundo (conhecimento do mundo) para interagir com o sistema" como mostra a figura 3.

Figura 3 - Conhecimento mundo e mente
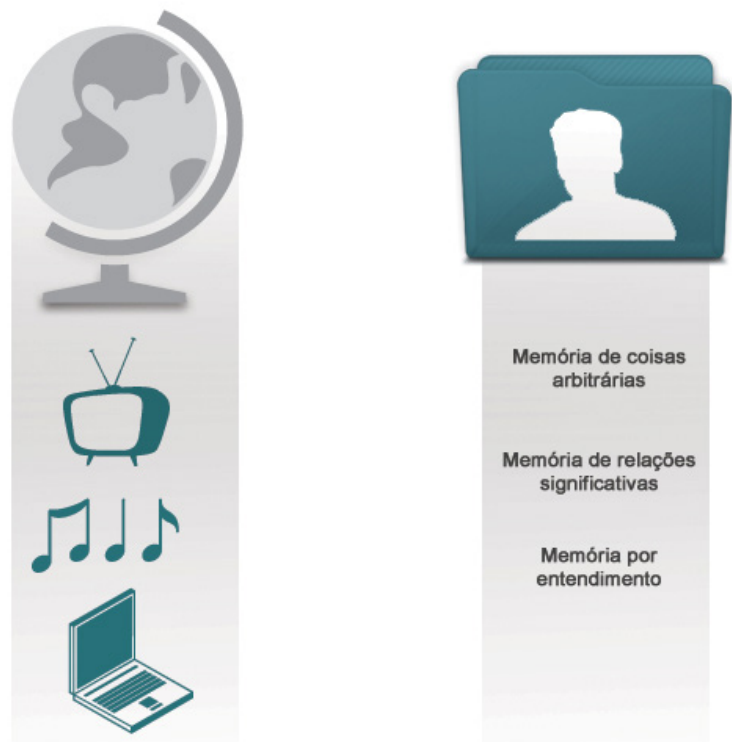

Fonte: Adaptado de Royo (2008). 
O conhecimento de mente é aquilo que já foi apresentado ao usuário e ficou registrado em sua memória. Conforme Norman (1990) existem três tipos de memória que o usuário utiliza dependendo das informações que precisa registrar:

- Memória de coisas arbitrárias: são as informações impostas a serem gravadas como, por exemplo, uma senha de computador, teclas que devem ser apertadas para executar tal função, uma data de aniversário.

- Memória de relações significativas: utiliza memórias já inseridas no usuário para determiná-la para um novo sistema que será mais facilmente compreendido, como por exemplo, utilizar uma interface já conhecida no mundo real que o usuário conseguirá utilizar por já conhecê-la.

- Memória por entendimento: pensando que para assimilar as informações o ser humano precisa compreendê-las, essa memória é a de maior eficácia. Neste caso é necessário que o usuário encontre o significado do objeto pelas pistas dadas e faça a conexão do seu significado com o objeto.

Sendo então "conhecimento da mente" o aprendizado que fica gravado na memória, o ser humano também tem o conhecimento de mundo que pode ser chamado de memória externa. Essa memória externa são informações necessárias nas atividades diárias e não estão implícitas na mente, são como lembretes, anotadas para não serem esquecidas como calendários para situar a data, alarmes como lembrete de alguma reunião.

Em um projeto de interface gráfica, analisando o usuário envolvido, é necessário entender o contexto em que este interage com o sistema. O entendimento desta interação, segundo Preece, Rogers e Sharp (2007), pode ser conhecido ao aplicar-se a etnografia. A etnografia pode ser traduzida como "descrever a cultura", ou seja, observar o usuário em seu ambiente de trabalho e encontrar uma ordem dentro de sua atividade. Esta observação pode ser feita por meio de conversas, reuniões, análise de documentos. Esta técnica é ideal para ser aplicada no começo do projeto, afirma Preece, Rogers e Sharp (2007), para que seja descoberta qual é realmente a necessidade do usuário, é possível descobrir o que as pessoas realmente fazem, e não somente o que elas dizem que fazem.

O estudo objetivo em relação às metas de experiência do usuário foi abordado nesta pesquisa, pois se verificaram princípios com alto índice de ligação com os elementos de hierarquização e arquitetura da informação. 


\section{Elements GRáficos da Interface}

O designer gráfico define quais são os elementos visuais mais adequados para a distribuição da informação em uma interface gráfica, assim como sua disposição e o uso da imagem nesse meio. Em uma interface, o projeto deve partir da escolha das informações a serem anexadas, disponibilizando-as de forma hierárquica, ordenada e com uma composição de linhas e cores arranjadas de forma que sejam capazes de atrair a atenção do usuário, apontando um caminho visual que facilite a absorção dessas informações (CUNHA, 2002).

Flusser (2007, p. 182) afirma: "o designer é [...] um conspirador malicioso que se dedica a engendrar armadilhas". O designer comunica, então, de uma forma planejada, manipulada. Os elementos gráficos são importantes para entender os motivos de constituição visual de uma interface e assim extrair conhecimentos práticos e empíricos.

Segundo Guillermo (2002, p. 91), no ambiente digital, a produção de imagens, em função da tecnologia envolvida, passa a depender do equipamento utilizado. Conforme o autor, os motivos "vão desde a resolução de telas dos monitores, capacidade de memória para "abertura" e armazenamento das imagens e a compatibilidade de programas". Fuentes (2006) aponta as seguintes limitações técnicas: baixa resolução e diferentes formatos de tela e softwares de navegação.

\section{Grid e Layout}

As características das grades e layouts mostram que uma interface gráfica precisa seguir alguns padrões aplicados à página inicial e as páginas internas. Nielsen e Tahir (2002) mostram uma série de análises realizadas à homepage (página inicial) de uma interface gráfica, que para eles é a página mais importante por ser o primeiro contato do usuário e ter as funções de transmitir o sentido do site e mostrar a relação com a concorrência e os serviços oferecidos. Estas funções estão intimamente relacionadas à grade e ao layout na medida em que os elementos que os compõem estão dispostos dentro das suas demarcações e apresentam características que podem ser replicados em áreas internas.

O layout de uma interface gráfica, conforme Nielsen e Tahir (2002), pode ser congelado ou fluido e é visualizado em duas dimensões: largura e comprimento. O layout fluido, na opinião dos autores, é o mais indicado por se adequar horizontalmente à maioria das resoluções de telas e por isso aproveita de forma mais eficiente a área visível. O layout congelado segue uma grade 
rígida (veja a comparação dos dois tipos, demonstrados por interfaces para web na figura 4), tendo como recomendação de largura máxima, segundo eles, de 770 pixels', baseada num padrão de resolução de tela de 800 × 600 pixels.

Figura 4 -Layout fluído, à esquerda e Layout congelado,à direita
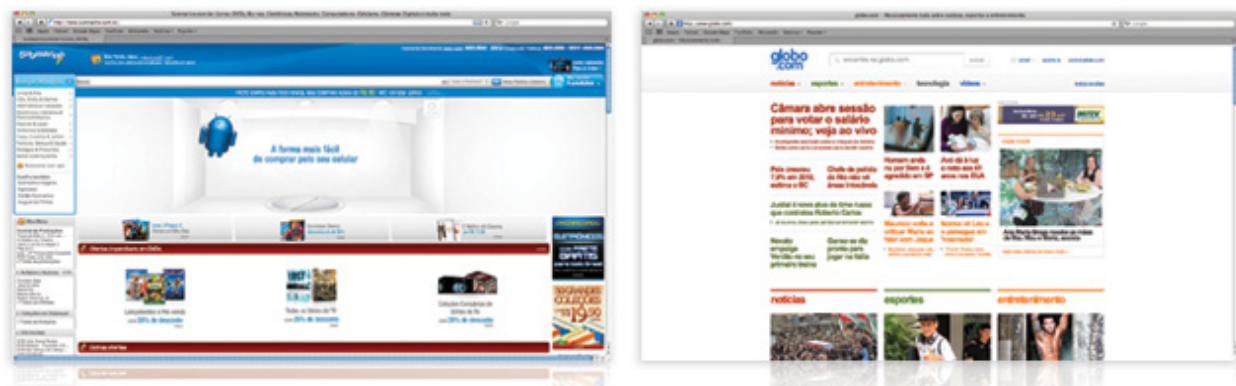

Fonte: Do autor.

Todavia, a resolução $800 \times 600$ pixels é um padrão mais antigo, não sendo o mais utilizado atualmente, como indica o W3Schools (2010), um website que realiza estatísticas mundiais a mais de dez anos a respeito de dados de usuários na Internet. Segundo o website, a resolução mais utilizada atualmente é de 1024 x 768 pixels, representando $20 \%$ do total, sendo que $76 \%$ utilizam uma resolução ainda maior. O padrão mais utilizado é ao mesmo tempo a menor resolução expressivamente significativa, não deixando dúvidas de que este é o modelo ideal de formato para se desenvolver uma interface de site na atualidade.

Em função disso, o website 960 Grid System (2013) disponibiliza exemplos de grades para vários softwares de edição gráfica. As grades possuem 960 pixels de largura, o que caracteriza o nome do website, e são divididas em doze ou dezesseis colunas. Assim como a de doze colunas, a grade de dezesseis garante a visualização adequada para o padrão de 1024 pixels de largura e, por possuir mais colunas, condiciona maior liberdade para o "encaixe" dos elementos. $\mathrm{Na}$ figura 5, segue um exemplo de uma interface gráfica para web que utilizou a grade de dezesseis colunas na sua concepção.

1 De uma forma mais simples, um pixel é o menor ponto que forma uma imagem digital, sendo que o conjunto de milhares de pixels formam a imagem inteira (FONSECA, 2011). 
Figura 5 -Grade de Dezesseis Colunas

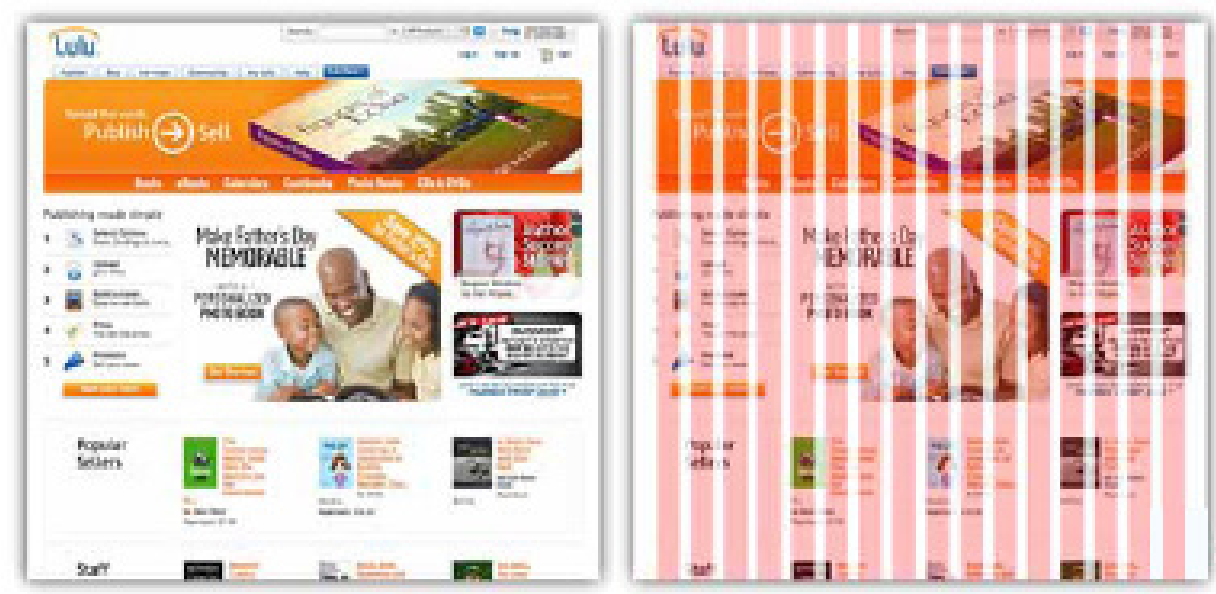

Fonte: 960 Grind System (2013).

O uso de grades garante a consistência e o alinhamento necessário para que os elementos gráficos sejam percebidos de forma lógica e entendidos na estrutura do layout. Além disso, disposições nas grades se repetem frequentemente, facilitando o aprendizado do usuário com a interface gráfica que Ihe parece familiar.

\section{Cor para Ambientes Digitais}

No design gráfico, a cor possui inúmeras funções. Conforme Cunha (2002), estas funções têm importância crucial no grau de harmonia visual e são um dos principais elementos que determinam a eficiência de uma solução de design gráfico. Ambrose e Harris (2003) escrevem que a cor oferece dinamismo, atrai a atenção e gera emoções no observador, as mesmas podem ser usadas para organizar elementos em uma interface gráfica, guiar o olhar e agrupar objetos semelhantes. Conforme características presentes na interface gráfica do website globo.com na figura 6. 
Figura 6 -Utilização de Cores para Organizar os Temas Principais do site globo.com

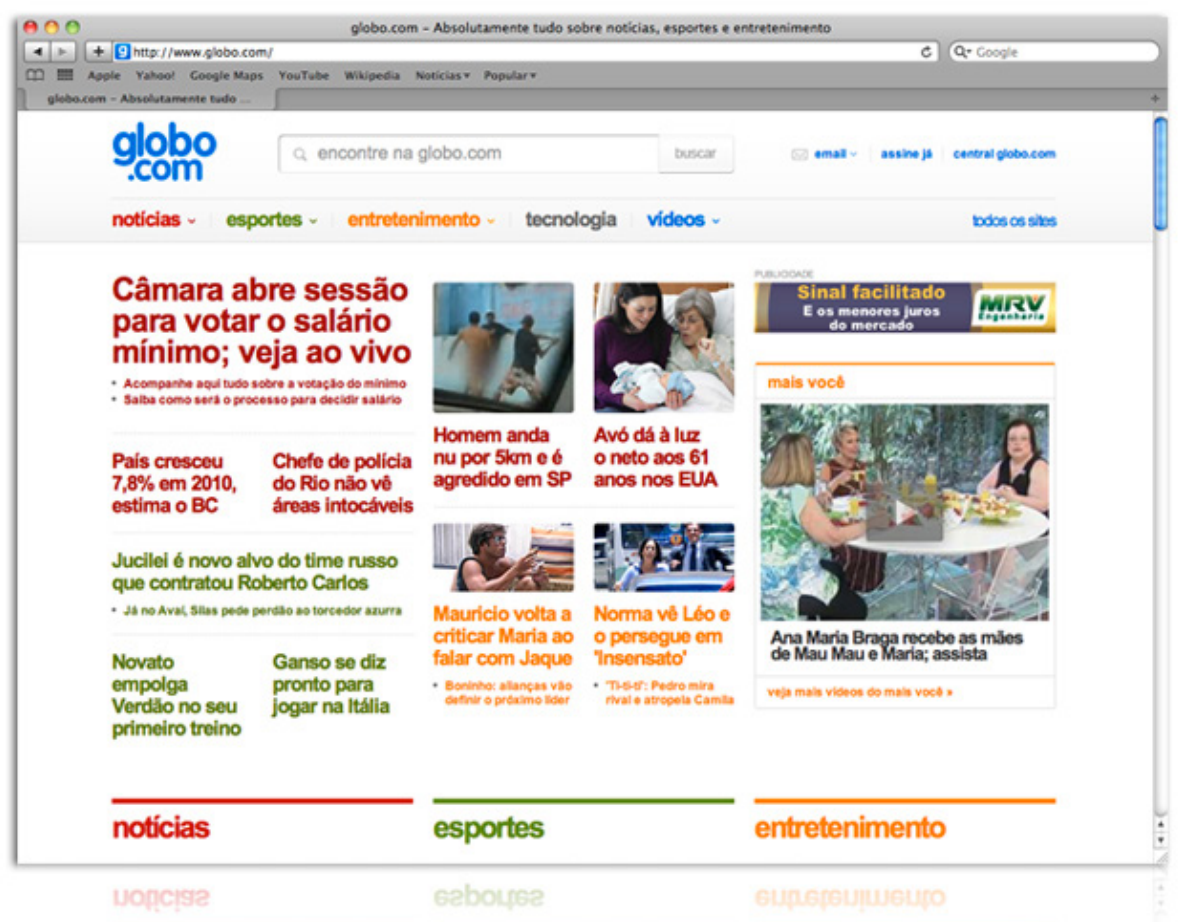

Fonte: Globo (2012)

Flusser (2007) escreve que as cores possuem significados, envolvem e programam os homens por fazerem parte do mundo codificado em que vivem. Ainda, segundo o autor, as cores são a maneira como aparecem as superfícies e, por isso, ganham a importância de portadoras de mensagens. Neste caso, a superfície é a interface gráfica presente na tela, responsável em atribuir os significados das cores.

Segundo Guimarães (1996), na percepção de uma interface gráfica, as cores são um dos códigos mais eficientes por serem estímulos primários e naturais ao qual se aprendem muito antes das formas e dos tamanhos. Além disso, Samara (2007) escreve que as cores afetam psicologicamente o observador. Os significados psicológicos de algumas cores podem ser vistos na figura 7. 
Figura 7 -Psicologia das Cores

\section{VERMELHO \\ Vibrante, umas cores mais notáveis. \\ Estimulante ao sistema nervoso. Invoca adrenalina. Causa raixa impulsăo, sentimento de} paixăo e libído.
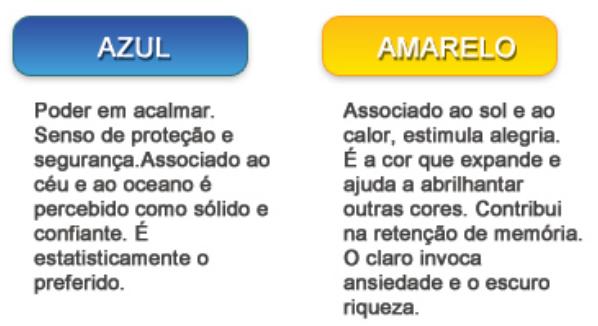

MARROM

Associado a terra parece confortável e seguro. A solidez da cor transmite sentimentos de eternidade e valores duradouros. Suas qualidades săo vistas como resistente e ecológico.

\section{ROXO \\ Misterioso e equivocado. Próximo do preto denota morte, mais azulado se torna nostálgico e sonhador. Próximo do rosa é dramático e energético, saturado parece mágico.}

VERDE
Com o menor
comprimento de onda é
a cor mais relaxante do
espectro. Associado a
natureza e a alimentaçăo
faz sentir seguro.
Quanto mais claro, mais
energético e jovial.
Năo representa doença
ou decaimento.

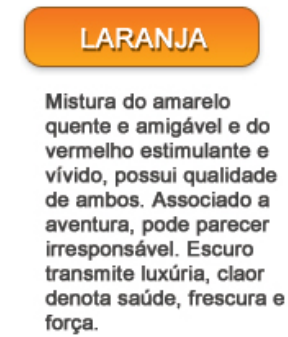

\section{CINZA}

Associado a terra parece confortável e seguro. A solidez da cor transmite sentimentos de eternidade e valores duradouros. Suas qualidades săo vistas como resistente e ecológico.

Em uma interface gráfica, Ambrose e Harris (2003) explicam que a visualização das cores é possível pela natureza da adição entre o vermelho, o verde e o azul do sistema Red, Green, Blue - RGB. lida (2000) aponta três variáveis que identificam as cores: matiz ou gama (qualidade da cor, referente a sua posição espectral), claridade, luminosidade ou brilho (quantidade de branco ou preto na composição) e saturação ou intensidade (pureza da cor).

Ciente do impacto das cores, estas contribuem nas diferentes maneiras expostas para a elaboração de uma interface gráfica, ao qual seu planejamento determina grande parte do sucesso da interface. Utilizá-las coerentemente é uma forma de garantir para que os elementos tenham benefícios dos princípios de legibilidade e usabilidade.

\section{Tipografia para Ambientes Digitais}

O interesse em torno da tipografia no design gráfico se traduz pela preocupação quanto à "verbalização visual" do simbolismo do seu conteúdo. Farias (1998) define tipografia como as práticas de criação e utilização de caracteres ortográficos (letras) e para-ortográficos (números e pontuações) para reprodução.

No meio digital, a tipografia está independente para os arquivos de fontes, sendo a fonte, conforme Gruszynski (2008), um conjunto completo de 
letras, números e sinais que seguem o mesmo padrão de desenho. Ou seja, a denominação fonte é muito mais vasta do que a referência aos arquivos eletrônicos. Ainda, conforme a autora, um conjunto de fontes tipográficas de mesmas características e variações relativas à espessura, peso, inclinação, denomina-se família. Entendesse aqui que as fontes tipográficas, constituintes ou não a uma família, no meio digital, estão em arquivos, não são os arquivos.

As fontes carregam consigo uma expressão formalizada da tipografia. $\mathrm{Na}$ opinião de Farias (1998), pela observação da história, a tipografia sempre foi condicionada pelo propósito de agir como uma interface visual da linguagem verbal, excluindo o tempo pós-moderno que foge ostensivamente a este padrão. Pode-se dizer que a tipografia no pós-moderno, conforme Gruszynski (2008), está além da escrita.

Dessa forma, o sentido do texto está oculto no simbolismo dos caracteres combinantes materializados na fonte que expõe sua aparência tipográfica, por isso possível de ser cronologicamente metamórfica, como é apresentada. Rocha (2005, p. 11) afirma que é "inquestionável a condição da tipografia como recurso de estilo imprescindível na linguagem gráfica". Conclui-se que, inclusive no meio digital, as fontes tipográficas sofrem mudanças ao longo do tempo e precisam ser tratadas, além de elementos de expressão visual, de forma a adequá-las ao meio. Essa adequação se faz pelo entendimento da atuação da fonte no meio digital.

Os caracteres no sistema digital, de acordo com Rocha (2005), são reproduzidos a partir das informações bitmap armazenadas nas fontes, conforme visualizado na figura 8. Segundo o autor, três aspectos são analisados em uma fonte digital: a qualidade da ideia, do desenho e da resolução técnica.

Figura 8 -Informações Bitmaps Armazenadas na Fonte Palatino Bold

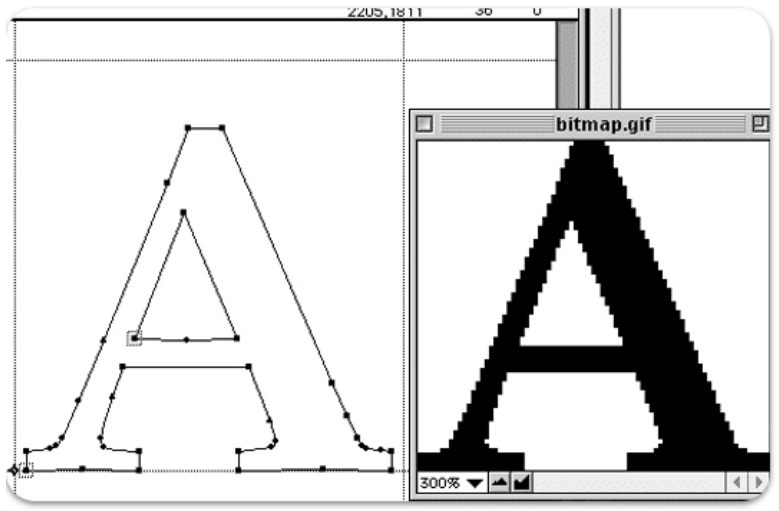

Fonte: Tipografia (2013). 
Se o texto será lido na tela, desenhe-o para ela. Esta é opinião de Bringhurst (2005). O autor diz que existem diferenças na composição de tipografias para impressão e para tela. Explicando que quando o texto é apresentado de forma grosseira o olho procura uma distração na tela, fazendo com que o objetivo de captar atenção do usuário se disperse. Afirma que a tela já é um ambiente fugidio, o que o torna interessante para propagandas e mensagens rápidas, mas problemático para textos maiores. Então Bringhurst (2005, p. 209) afirma que "as boas fontes de texto para tela, portanto são aquelas com baixo contraste, torso grande, interiores abertos, terminais sólidos e serifas retas ou sem serifas".

A qualidade da ideia para uma interface gráfica diz respeito a transposição dos valores sobre algo específico à tipografia ou simplesmente à função de uma boa leitura. O seu desenho diz respeito à forma que condiciona um estilo e a legibilidade. $O$ desenho é muito importante para a personificação e a criação de Identidade da interface. Os usuários podem lembrar-se do desenho da tipografia e usufruir da qualidade da sua ideia. A resolução técnica compreende a interpretação das fontes digitas por diversos softwares.

\section{Infográficos}

Desenvolver infográficos é um caminho de grande valia em propor aos usuários uma experiência exploratória mais aprofundada diante das informações disponíveis em uma interface gráfica. A mesma, como elemento gráfico de uma interface, possui condição de trabalhar com expressões visuais de assuntos abordados em capítulos anteriores, como a psicologia arquetípica e a semiótica.

O design de informação, segundo Wildbur e Burke (1998), consiste na seleção, organização e apresentação da informação a um determinado público, tendo como função primordial a comunicação eficiente dessa informação. Os autores escrevem que o design de informação transpõe a informação para um plano visual capaz de transmitir a sua essência aos observadores, de modo a ser captada facilmente.

Nesse contexto o termo infografia, segundo Souza e Giering (2009), tem sua origem nas palavras informação (info) e gráfica (grafia) e se refere ao caráter demonstrativo que explica os fenômenos textuais e discursivos de uma escrita. A infografia, desse modo, no design de informação, é aplicada ao desenvolvimento de infográficos.

Um infográfico, segundo Souza e Giering (2009), enuncia ao observador 
o cumprimento do designer em "descrever para explicar", no sentido de transformar informações textuais em informações visuais que complementam este primeiro.

Os infográficos feitos para os meios digitais, de acordo com Raymundo (2009 apud SALAVERRÍA, 2001), lidam com elementos multimídia (imagem, áudio, animação, vídeo, texto, entre outros) que devem manter uma unidade entre si de maneira a serem compreendidos, tanto isoladamente, quanto no todo. Ainda conforme Raymundo (2009 apud SALAVERRÍA, 2001), num ambiente virtual, os diferentes atrativos fixam a atenção do usuário e, em função disso, sua exploração aos elementos informativos pode não apreender a mensagem em sua totalidade.

No exemplo da figura 9 o usuário interage com o infográfico, que é também animado, para descobrir qual é a Nossa Senhora que mais the cabe pedir ajuda na situação presente. A cada resposta informada as imagens vão sumindo, restando por último apenas a Nossa Senhora indicada, juntamente com um texto explicativo.

Figura 9 - Infográfico Animado e Interativo para Descobrir a Nossa Senhora que lhe é Indicada

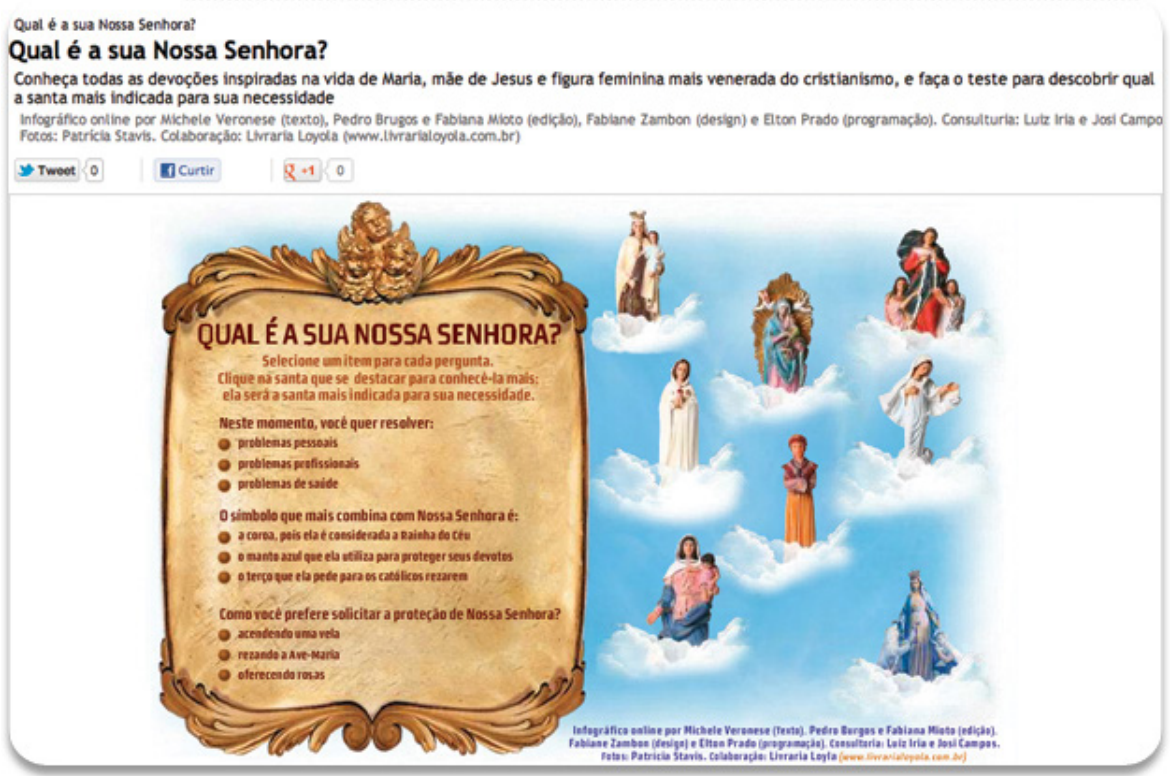

Fonte: Veronese et al. (2013).

Estas características demonstram que existe a oportunidade para os infográficos suporem a imaginação dos usuários por meio de uma linguagem visual, que pode inclusive ser interativa e animada. $O$ uso deste elemento gráfico, também está associado aos conceitos anteriormente abordados sobre arquitetura da informação. 


\section{ESTUDO DE CASO: INTERFACE WEB APPLE BRASIL}

Como forma de justificar a importância contextual abordada até então, foi selecionada a interface web da Apple Brasil. Conforme a figura 10, a análise foi gerada a partir de referências da grade e posicionamento de elementos.

Figura 10 - Grid website Apple Brasil

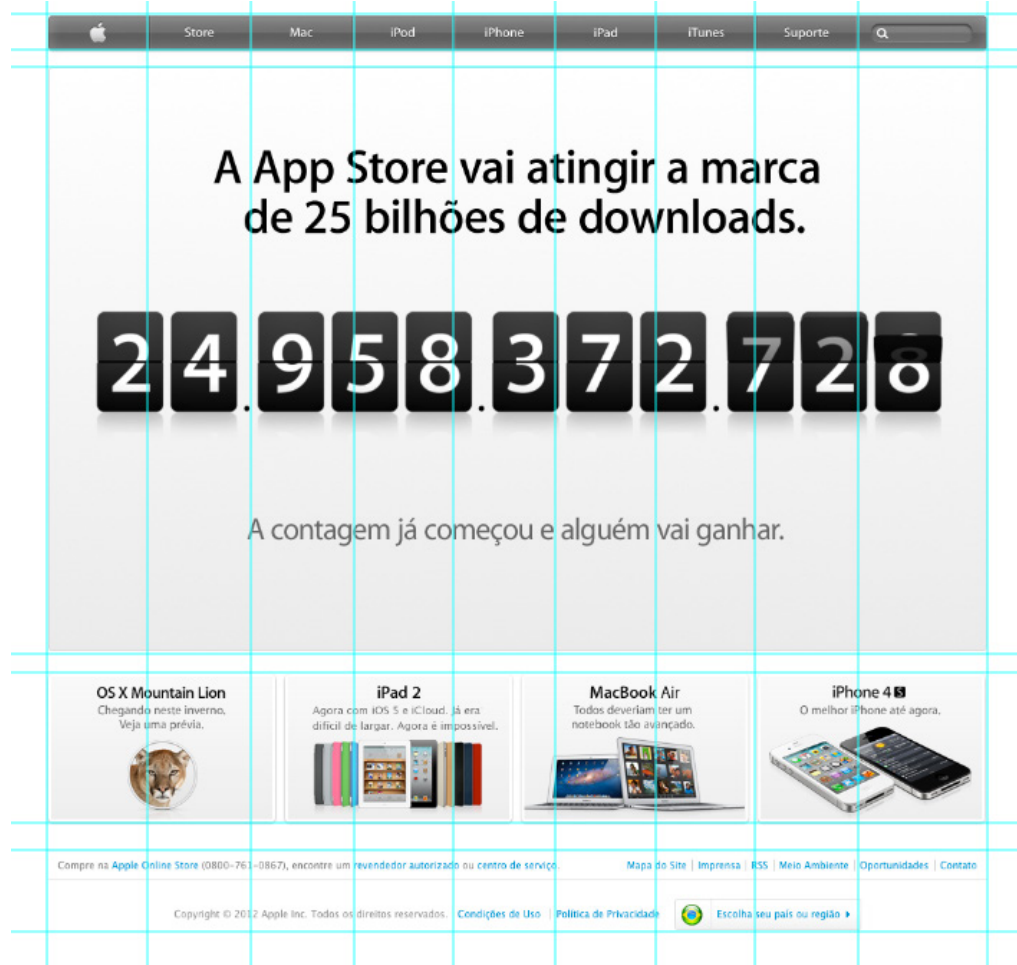

Fonte: Do autor.

A interface gráfica em questão possui uma disposição dos elementos na grade de maneira mais horizontal. A grade também é facilmente identificada por módulos, ou seja, existem espaços com tamanhos específicos para cada elemento gráfico, evidenciando uma hierarquia visual. Também foi notado que em um primeiro impacto, a interface gráfica segue um padrão visual adotado institucionalmente. Posteriormente, foram feitas análises através da lista de verificação de características, conforme figura 11. 
Figura 11 - Lista de Verificação de Características website Apple Brasil
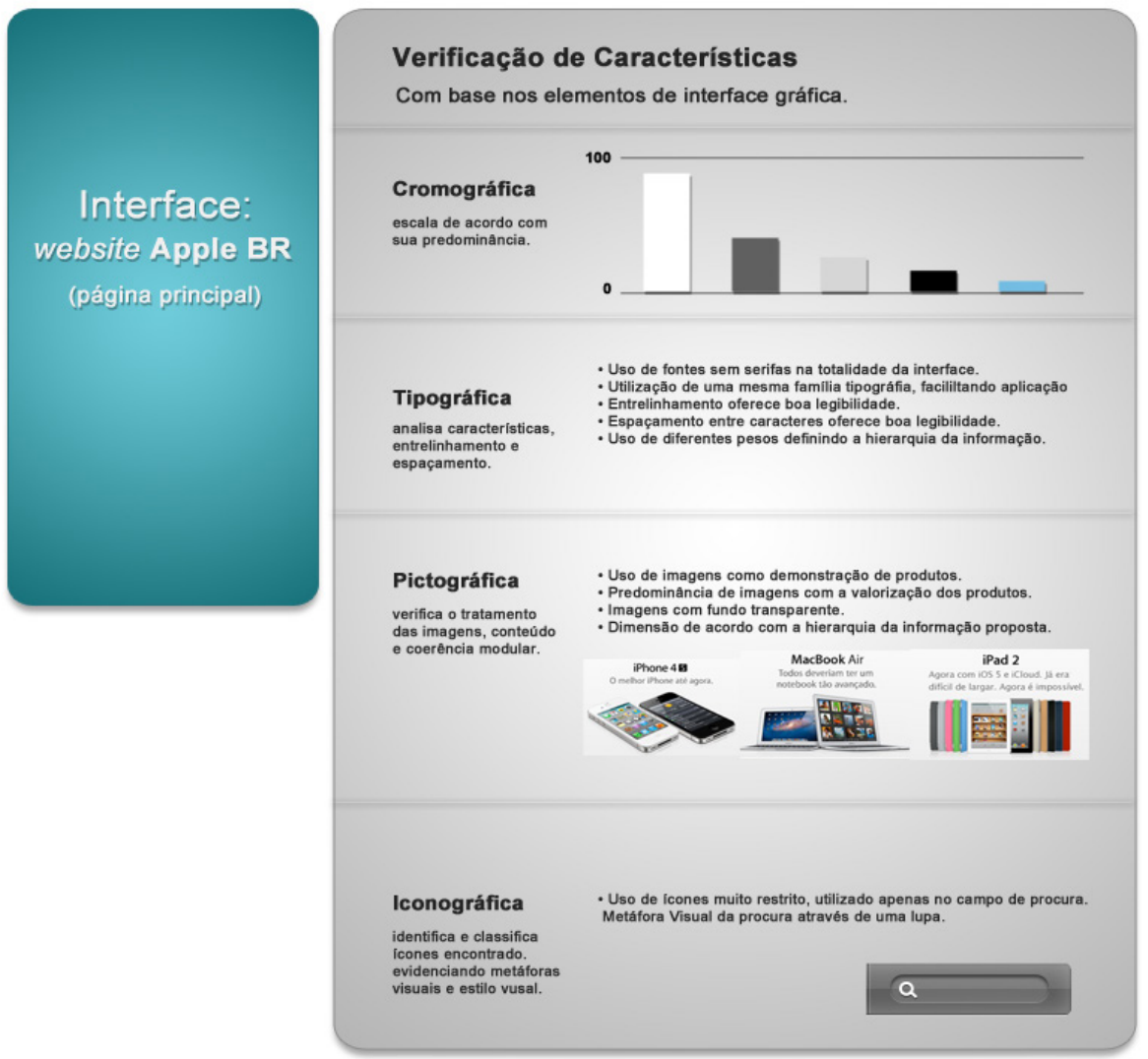

Fonte: Do autor.

Logo na primeira análise quanto ao item cromográfico, foi possível notar uma paleta de cores frias, porém neutras. Neste caso, as cores se tornam praticamente invisíveis, destacando em partes todas as imagens. Essa escolha deixa o usuário confortável, porém se uma boa escolha de imagens não for feita o mesmo usuário não evidencia áreas de destaque. Grande parte da paleta é constituída por tons de cinza, muito utilizada em outros materiais institucionais da empresa.

Em questões tipográficas, a interface gráfica utiliza fontes sem serifas em sua totalidade e, conforme abordado em itens anteriores, gera alto grau de legibilidade e usabilidade em relação ao usuário. A interface em questão, também utiliza uma família tipográfica, sendo modificada apenas pelos pesos. Isso faz com que a hierarquia de informação seja bem aplicada. Tanto o entrelinhamento e o espaçamento de caracteres são dispostos de maneira muito clara, oferecendo boa legibilidade ao usuário.

Nos aspectos pictográficos, a valorização da imagem traz notoriedade dos produtos sobre o usuário. As mesmas são dispostas de modo a agregar valor. 
E, aplicadas de maneira coerente sobre o fundo neutro, chamam atenção do usuário. Por fim, a dimensão destas imagens age de acordo com a hierarquia de informação proposta. No ponto iconográfico, o uso de ícones é muito restrito e identificado apenas no campo de procura, mas com o uso claro de metáforas visuais.

Concluindo a análise da interface gráfica em questão, chegou-se ao fato de que os aspectos respeitam a relação da mesma com o usuário. Nem sempre todos os elementos gráficos precisam ser explorados de maneira explícita, eles necessitam ser bem aplicados gerando sintonia com o usuário.

\section{CONSIDERAC̣ÕES FINAIS E FUTURAS CONTRIBUIC̣̃̃ES}

O designer gráfico possui um grande nível de responsabilidade ao projetar uma interface gráfica e, para isso, precisa observar fundamentos abordados nesta pesquisa, como, elementos gráficos, arquitetura da informação e, também, preocupação com o usuário.

O estudo da interface gráfica trouxe contribuições em aspectos de interação com o usuário e em como os estudos de arquitetura de informação e experiência do usuário podem influenciar diretamente em elementos gráficos do cotidiano de um designer gráfico. Concluindo que uma interface gráfica é muito mais do que um aspecto visual representado em uma tela, por trás existe um conceito a ser interpretado ao usuário. Facilitando o estudo em relação ao mesmo, que muitas vezes em um projeto de interface gráfica ocorrem de maneira empírica.

Por fim, a realização pessoal e profissional dos pesquisadores, em contribuir com conhecimentos sobre interfaces gráficas e disponibilizar para futuros pesquisadores o resultado da pesquisa. Lembrando que o caminho adotado pelos pesquisadores se mostrou coerente, mas a pesquisa tem o intuito de ser colaborativa, da forma com que outras possibilidades possam fazer com que o resultado venha a contribuir de maneira ainda mais completa. 


\section{REFERÊNCIAS}

960 Grid System. Disponível em:<http://960.gs/>. Acesso em: 5 maio 2013.

AMBROSE, Gavin; HARRIS, Paul. The Fundamentals of Creative Design. Suíça: AVA Book, 2003.

ANDRADE, Antonio Luis Lordelo. Usabilidade de interfaces Web: avaliação heurística no jornalismo on-line. Rio de Janeiro: E-papers, 2007.

BRINGHURST, Robert. Elementos do estilo tipográfico. São Paulo: Cosac \& Naify, 2005.

CUNHA, Frederico Carlos. A proteção legal do design. 2. ed. Rio de Janeiro: Lucerna, 2002.

DOMINGUES, Diana. Criação e interatividade na ciberarte. São Paulo: Experimento, 2002.

Farias (1998) - falta ref.

FLUSSER, Vilém. O mundo codificado. São Paulo: Cosac Naify, 2007.

FONSECA, William. O que é pixel? Disponível em: <http://www. tecmundo.com.br/imagem/203-o-que-e-pixel-.htm>. Acesso em: 12 fev. 2011.

FUENTES, Rodolfo. A prática do design gráfico. São Paulo: Rosari, 2006.

GLOBO. Disponível em: <WWW.globo.com>. Acesso em: 12 jul. 2012.

GRUSZYNSKI, Ana Cláudia. Design gráfico: do invisível ao ilegível. São Paulo: Rosari, 2008.

GUILLERMO, Alvaro. Design: do virtual ao digital. São Paulo: Rio Books, 2002.

GUIMARÃES, Lia Buarque de Macedo. Aspectos perceptivos da interação homem-computador. In: WORKSHOP, 1996. Florianópolis. Anais... Florianópolis, 1996.

IIDA, Itiro. Ergonomia: projeto e produção. 6. ed. São Paulo: Edgard 
Blücher, 2000.

LYNCH, Patrick; HORTON, Sarah. Manual de estilo web: principios de diseño básico para la creación de sitios web. 2. ed. Barcelona: Gustavo Gili, 2004.

MEMÓRIA, Felipe. Usabilidade de interfaces e arquitetura da informação: navegação estrutural. In: CONGRESSO INTERNACIONAL DE ERGONOMIA E USABILIDADE, DESIGN DE INTERFACES E INTERAÇÃO HUMANO-COMPUTADOR, 2., 2003. Rio de Janeiro. Anais... Rio de Janeiro: USIHC, 2003.

MOURA, Mônica. A interatividade no design de hipermídia. In: CONGRESSO DE PESQUISA E DESENVOLVIMENTO EM DESIGN, 7.; 2006, Curitiba. Anais... Curitiba, 2006.

NIELSEN, Jakob; TAHIR, Marie. Homepage: 50 websites desconstruídos. Rio de Janeiro: Campus, 2002.

NORMAN, Donald A. A Psicologia dos objetos cotidianos. Madri: Nerea, 1990.

PREECE, Jennifer; ROGERS, Yvonne; SHARP, Helen. Design de interação: além da interação homem - computador. Porto Alegre: Bookman, 2007.

ROCHA, Claudio. Projeto tipográfico: análise e produção de fontes digitais. São Paulo: Rosari, 2005.

ROSA, José Guimarães Santa; MORAES, Anamaria de. Avaliação de projetos no design de interfaces. Teresópolis: 2AB, 2008.

ROYO, Javier. Design digital. São Paulo: Rosari, 2008.

SALAVERRÍA, Ramón. Aproximación al concepto de multimedia desde los planos comunicativo e instrumental. Estudios Sobre el Mensaje Periodístico, Madrid, n. 7, 2001. Disponível em: <http:// pendientedemigracion.ucm.es/info/periol/Period_I/EMP/ Numer_07/7-5-Inve/7-5-13.htm>. Acesso em: 12 maio 2013.

SAMARA, Timothy. Design elements: a graphic style manual. Nova York: Rockport Publishers, 2007.

SOUZA, Juliana Alles de Camargo de; GIERING, Maria Eduarda. O 
infográfico: a multimodalidade e a semiolinguística. Revista Anpoll, Belo Horizonte, v. 2, n. 27, 2009.

TIPOGRAFIA. Disponível em:< http://tipografos.net/glossario/fontesdigitais.html>. Acesso em: 5 maio 2013.

VERONESE, Michele et al. Qual PE a sua Nossa Senhora? Super Interessante. Disponível em:< http://super.abril.com.br/multimidia/ info_297195.shtml>. Acesso em: 5 jun. 2013.

W3SCHOOLS. Learn to create websites. Disponível em: <http://www. w3schools.com>. Acesso em: 19 nov. 2010.

WILDBUR, Peter; BURKE, Michael. Infográfica: soluciones innovadoras en el diseño contemporáneo. Barcelona: Gustavo Gili, 1998. 